\title{
Experimental Study on Mixture Ratio of Modified Mud
}

\author{
Zhiqiang LIª, Sen YANG ${ }^{b^{*}}$, Guoqing WANG ${ }^{*}$ \\ College of Water Conservancy \& Architectural Engineering, Shihezi University, Shihezi 832000, \\ China \\ azhiqiangli2023@163.com; b734885028@qq.com; c1543776250@qq.com \\ ${ }^{*}$ Corresponding Author: Sen YANG, Guoqing WANG. College of Water Conservancy \& Architectural \\ Engineering, Shihezi University.
}

Keywords: modified raw soil, compressive strength, orthogonal test, optimal mixture ratio

Abstract: Single factor test was applied to study on the engineering properties of modified mud, by which the reasonable range of grass, cement, lime, and glutinous rice were determined. And then, orthogonal test method was used to investigate the influence on the compressive strength of the modified mud, and the results were analyzed by range analysis, variance analysis and factor analysis. The experimental results show that the order of the influence of on the compressive strength of the modified mud was Grass A > glutinous rice D > cement B > quick lime C. Finally, the optimal mixture ration of modified mud was determined.

\section{Introduction}

Researches show that the raw soil mixed with grass could improve the flexural strength, mixed with fly ash could improve the long-term, mixed with cement could improve the compressive strength, and mixed with quick lime could improve the water resistance [1-3]. Therefore, this paper selects the Shihezi farm soil, mixed with grass, fly ash, cement and quick lime, to study the engineering characteristics of the modified raw soil samples, which aims at finding the best mixture ration of modified soil to improve the compressive strength, bending strength and durability.

\section{Single Factor Test}

\section{Experimental material.}

(1) Clay: clay supplied by the 150 Shihezi Regiment.

(2) Cement: 32.5R composite Portland cement.

(3) Quick lime: supplied by Shihezi 151 Regiment.

(4) Grass: Wheat straw, the length is less than or equal to $50 \mathrm{~mm}$.

(5) Glutinous rice: bought from Supermarket.

(6) Water: Tap water.

Single Factor Test and Analysis. The compressive strength of the concrete, cement, lime and clay was studied by single factor experiment, and the curve of compressive strength was shown in Fig.1.

In Fig.1 (1), it can be seen that when the content of grass is $[0 \%, 1 \%]$, the compressive strength of the modified mud block decreases gradually. Therefore, the reasonable range of the content of the grass is $[0 \%, 0.25 \%]$.

In Fig.1 (2), it can be seen that when the content of cement is [0\%, 5\%], compressive strength of modified mud block gradually decreased; when the content of cement is [5\%, 20\%], compressive strength of modified mud block gradually increases; when the content of cement is [15\%, 20\%], compressive strength of modified the mud block is significant. Therefore, the reasonable range of the content of cement is $[15 \%, 20 \%]$. 

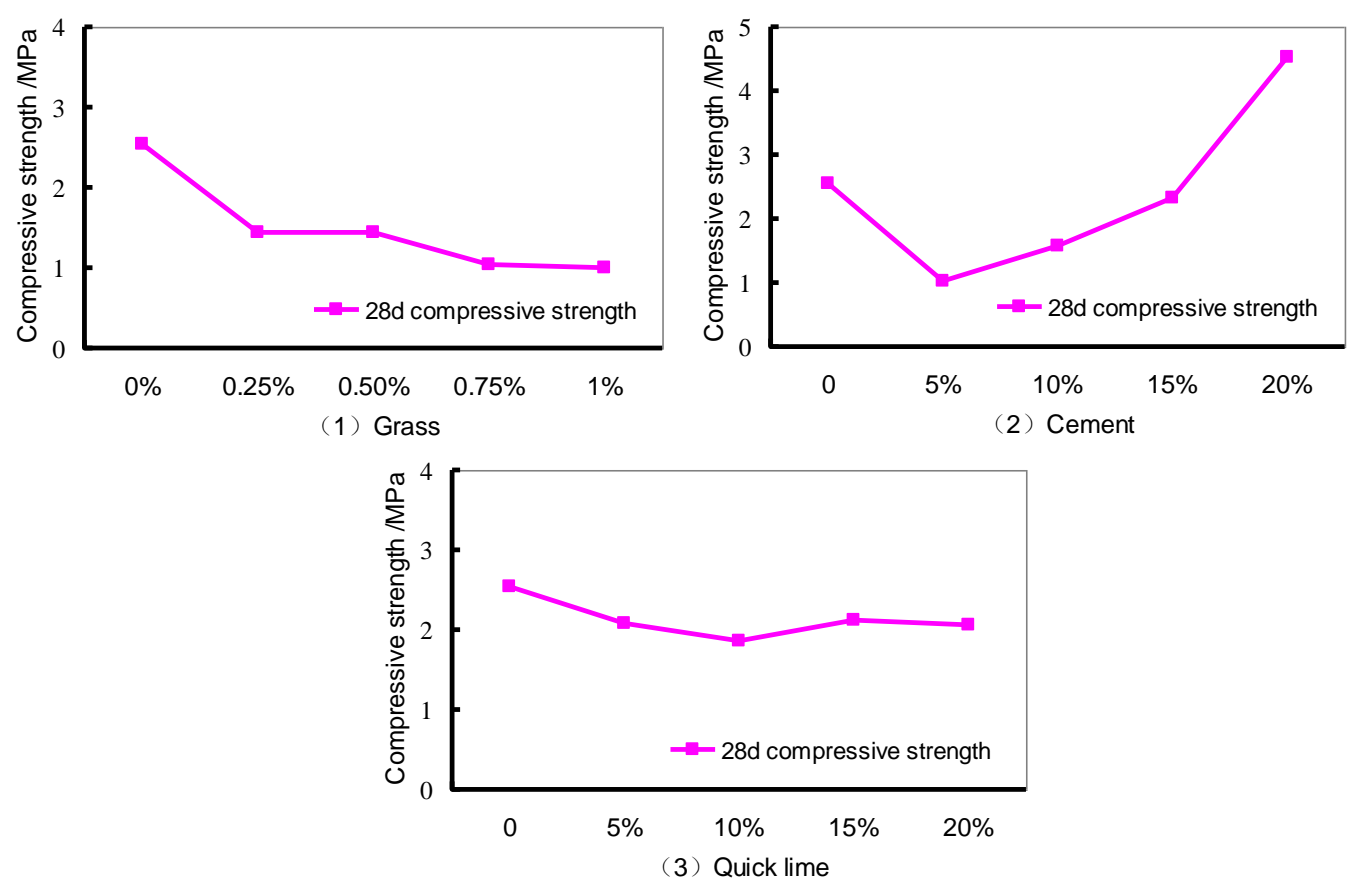

Fig.1 Modified mud block compressive strength of the single factor

In Figure 1(3), it can be seen that when the content of lime is [0\%, 10\%] and [15\%, 20\%], compressive strength of modified mud block decreased gradually; when the content of lime is [10\%, $15 \%$ ], compressive strength of modified mud block gradually increased. Therefore, the reasonable range of the content of lime the content of $[0 \%, 5 \%]$.

Through the single factor test of raw soil, mixed with glutinous rice, mud test block fermentation caused by swell, according to the results of the relevant literature, the final determination of the reasonable range of glutinous rice is $[0 \%, 10 \%]$.

\section{Orthogonal test}

Orthogonal experimental design. Based on the optimal values of the factors obtained from the single factor experiment, the interval of each parameter was refined. In order to reduce the test workload, orthogonal design method was used. 4 factors were determine: Grass (factor A), cement (factor B), quick lime (factor C), and glutinous rice (factor D), and each factor had 3 levels as shown in table1.

Table.1 The factor's level of test

\begin{tabular}{ccccc}
\hline Factor & Grass A $(\%)$ & Cement B $(\%)$ & Quick lime C $(\%)$ & Glutinous rice D $(\%)$ \\
\hline Test1 & 0 & 15 & 0 & 0 \\
Test2 & 0 & 17.5 & 2.5 & 5 \\
Test3 & 0 & 20 & 5 & 10 \\
Test4 & 0.15 & 15 & 2.5 & 10 \\
Test5 & 0.15 & 17.5 & 5 & 0 \\
Test6 & 0.15 & 20 & 0 & 5 \\
Test7 & 0.25 & 15 & 5 & 5 \\
Test8 & 0.25 & 17.5 & 0 & 10 \\
Test9 & 0.25 & 20 & 2.5 & 0 \\
\hline
\end{tabular}

Test results. According to the test method of GB/T 4111-2013, the compressive strength of the modified mud block can be obtained as shown in table 2 .

Table.2 The results of compressive strength

\begin{tabular}{cccccccccc}
\hline Test & Test 1 & Test 2 & Test 3 & Test 4 & Test 5 & Test 6 & Test 7 & Test 8 & Test 9 \\
\hline $\begin{array}{c}\text { 28d Compressive } \\
\text { strength } / \mathrm{MPa}\end{array}$ & 3.45 & 2.38 & 1.87 & 2.25 & 3.71 & 7.60 & 5.71 & 4.11 & 5.68 \\
\hline
\end{tabular}


According to results of table 1 and table 2, the range analysis of orthogonal test can be obtained as shown in table.3.

Table .3 The range analysis of orthogonal test

\begin{tabular}{cccccc}
\hline \multirow{2}{*}{ Test } & \multirow{2}{*}{ Range analysis } & \multicolumn{4}{c}{ Influence factor } \\
\cline { 2 - 5 } & $I_{\mathrm{j}}$ & 7.701 & $\mathrm{~B}$ & $\mathrm{C}$ & $\mathrm{D}$ \\
\hline & $I_{\mathrm{j}}$ & 13.560 & 11.409 & 15.159 & 12.840 \\
28d & $I \mathrm{I}_{\mathrm{j}}$ & 15.501 & 10.200 & 10.311 & 15.690 \\
Compressive & $K_{1}$ & 15.150 & 11.289 & 8.229 \\
strength / Mpa & $K_{2}$ & 4.567 & 3.803 & 5.053 & 4.280 \\
& $K_{3}$ & 5.167 & 3.400 & 3.437 & 5.230 \\
& $R$ & 2.600 & 5.050 & 3.763 & 2.743 \\
& $R$ & 1.650 & 1.616 & 2.487 \\
\hline
\end{tabular}

It can be seen that order of the influence of on the compressive strength of the modified mud was Grass A > glutinous rice D > cement $\mathrm{B}>$ quick lime $\mathrm{C}$.

Factors Analysis of Compressive Strength. According to the orthogonal test, the compressive strength of each factor at different levels can be obtained by factors analysis, as shown in Fig. 2 .
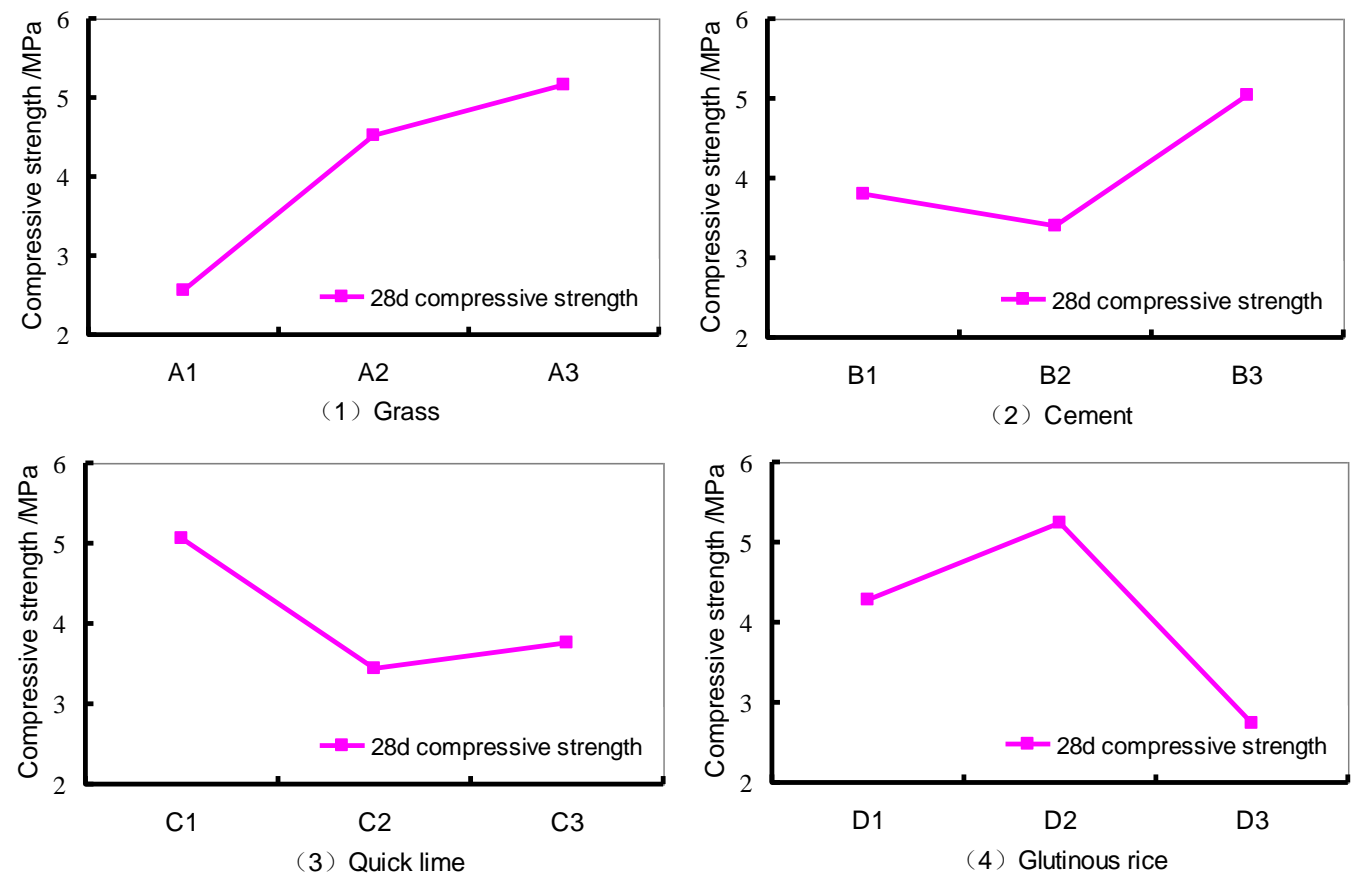

Fig.2 Modified mud block compressive strength factors index analysis

In Figure 2(1), it can be seen that when the content of grass is $[0 \%, 0.25 \%]$, the compressive strength of the modified mud block gradually increased, so the optimal ratio of the content of grass can be determined as $0.25 \%$.

In Figure.2(2) it can be seen that when the cement content is [15\%, 17.5\%], compressive strength of modified mud brick gradually decreased, when the cement content is [17.5\%, 20\%], compressive strength of modified mud block gradually increases, therefore, the optimal ratio of the content of cement can be determined as $20 \%$.

In Figure.2(3) it can be seen that when the content of lime is [0\%, 2.5\%], compressive strength of modified mud brick gradually decreased, when the content of lime is [2.5\%, 5\%], the compressive strength of raw soil blocks gradually increased, to consider the issue, so the durability of the earth, the optimal ratio of the content of lime can be determined as $5 \%$.

In Figure.2(4) it can be seen that when the rice content was [0\%, 5\%], compressive strength of modified mud block gradually increases, when the cement content is [5\%, 10\%], compressive strength of modified mud block decreased gradually, therefore, the optimal ratio of the content of glutinous rice can be determined as $5 \%$. 
The optimal mixture ration of modified mud was determined as A3B3C3D2 by factors analysis. The content of grass was $0.25 \%$, the content of cement was $20 \%$, the content of quick lime was $5 \%$, and the content of glutinous rice was $5 \%$.

\section{Variance analysis.}

Table .4 The variance analysis of orthogonal test

\begin{tabular}{ccccccc}
\hline Index & Factor & Sum of squares & Freedom & Fthan & F critical value & Significance \\
28d & $\mathrm{A}$ & 10.994 & 2 & 3.682 & $\mathrm{~F}_{0.01}=8.65$ & $*$ \\
compressive & $\mathrm{B}$ & 4.439 & 2 & 1.487 & $\mathrm{~F}_{0.05}=4.46$ & -- \\
strength & $\mathrm{C}$ & 4.384 & 2 & 1.467 & $\mathrm{~F}_{0.10}=3.11$ & -- \\
& $\mathrm{D}$ & 9.447 & 2 & 3.163 & & $*$ \\
\hline
\end{tabular}

Note: when $\mathrm{F}>\mathrm{F}_{0.01}$, the factor has significantly, marked as $* * *$; when $\mathrm{F}_{0.01}>\mathrm{F}>\mathrm{F}_{005}$, the factors significantly better, marked as **; when $\mathrm{F}_{0.05}>\mathrm{F}>\mathrm{F}_{0.10}$, the significant factors in general, marked as *; when $\mathrm{F}<$ $\mathrm{F}_{0.10}$ and this factor is not had a significant, labeled as "-".

According to the results of variance analysis of orthogonal test, it can be seen that the factors of Grass A and glutinous rice D have significant influence on the compressive strength of the modified mud block, followed by factors of cement B and quick lime $\mathrm{C}$.

The optimal mixture ration of modified mud was determined as A3B3C3D2 by variance analysis, which is similar to the results of factors analysis.

\section{Conclusions}

The most important conclusions that can be drawn from this study were as follows:

(1) The reasonable interval for the content of grass is $[0 \%, 0.25 \%]$, the content of cement content is $[15 \%, 20 \%]$, the content of quick lime content is $[0 \%, 5 \%]$, and the content of glutinous rice is $[0 \%$, $1 \%]$.

(2) The order of the influence of on the compressive strength of the modified mud was Grass A > glutinous rice $\mathrm{D}>$ cement $\mathrm{B}>$ quick lime $\mathrm{C}$.

(3) The optimal mixture ration of modified mud was A3B3C3D2. The content of grass was $0.25 \%$, the content of cement was $20 \%$, the content of quick lime was $5 \%$, and the content of glutinous rice was $5 \%$.

\section{Acknowledgments}

This project is sponsored by National Natural Science Foundation of China (Grant No. 51668053, 2015BAL03B02), and the High-Level Personnel Scientific Research Projects (RCZX201324).

\section{References}

[1] Yihong Wang, Jian Liang, Xiangying Zhang. China Civil Engineering Journal, 2015, 48(5): 98-107.

[2] Yihong Wang, Chunying Wang, Xianshun Li. Journal of Xi'an University Of Architecture And Technology (Natural Science Edition), 2006, 26 (4) : 73-77.

[3] Jin $\mathrm{Wu}$, Rongrong Hu, Seismic retrofitting and strengthening of engineering, 2013, 35 (5): 96-100. 